\title{
Lauraceae no município de Corumbá, Mato Grosso do Sul, BRASIL
}

\author{
Flávio Macedo Alves \& Iria Hiromi Ishii
}

\section{Resumo}

(Lauraceae no município de Corumbá, Mato Grosso do Sul, Brasil) O presente estudo teve por finalidade estudar as espécies da família Lauraceae no município de Corumbá-MS, baseado principalmente em coleções botânicas depositadas em herbários. Foram também realizadas coletas em várias regiões do município, principalmente na morraria Santa Cruz. São registradas para o município 10 espécies subordinadas a cinco gêneros, a saber: Aiouea trinervis, Aniba heringerii, Cassytha filiformis, Nectandra amazonum, N. cissiflora, N. gardneri, N. hihua, N. psammophila, Ocotea diospyrifolia e O. velloziana. Aniba heringerii é citada pela primeira vez para o Mato Grosso do Sul. Chaves para a identificação, descrições e ilustrações das espécies são apresentadas.

Palavras-chave: taxonomia, flora, Pantanal, morfologia.

\section{Abstract}

(Lauraceae in the municipality of Corumbá, Mato Grosso do Sul, Brazil) The present study was carried out in Corumbá-MS, aiming to make a survey of the occurrence of the species of the family based on herbarium specimens. Further collections were made also Santa Cruz hill. In this survey 10 species belonging to 5 genera were identified: Aiouea trinervis, Aniba heringerii, Cassytha filiformis, Nectandra amazonum, N. cissiflora, N. gardneri, N. hihua, N. psammophila, Ocotea diospyrifolia and O. velloziana. Aniba heringerii is reported for the first time for Mato Grosso do Sul, Brazil. Identifications keys, descriptions and illustrations of the species are presented.

Key words: taxonomy, flora, Pantanal, morphology.

\section{INTRODUÇÃo}

O nome Lauraceae é originado do gênero Laurus L., que em latim significa louro. Contudo, a literatura indica que esse nome é oriundo de laus - louvor, em referência às coroas de louro que eram oferecidas aos heróis em louvor a atos de bravura (Alves \& de Paula 1997).

Comum em regiões tropicais e subtropicais, a família é especialmente diversificada no sudeste da Ásia e norte da América do Sul (Judd et al. 1999), ou seja, é pantropical com poucos representantes em regiões temperadas (Vicentini et al. 1999).

Lauraceae é composta por aproximadamente 2500 espécies incluídas em 52 gêneros (Rohwer 1993a). Nas Américas ocorrem cerca de 29 gêneros e 900 espécies com grande diversidade na América Central (Vicentini et al. 1999). No Brasil é representada por 22 gêneros com alta diversidade nas florestas pluviais e também nas restingas e no cerrado (Barroso 2002).

Os inventários botânicos têm revelado que Lauraceae está em termos florísticos e econômicos, entre as mais importantes famílias de angiospermas, mas, infelizmente, a identificação de suas espécies é tarefa difícil (Baitello 2001). Por ser uma família de difícil identificação e aliado à pouca citação acerca da família na literatura local, fez-se necessário este estudo, a fim de subsidiar estudos florísticos, fitossociológicos, ecológicos, de conservação e recuperação de áreas degradadas no Pantanal.

O trabalho teve como objetivo identificar, descrever as espécies da família Lauraceae ocorrentes em Corumbá, Mato Grosso do Sul, estudar sua distribuição no município, bem como confeccionar chaves de identificação e ilustração para os gêneros e espécies a fim de facilitar sua identificação. 


\section{Material e Métodos}

O município de Corumbá está localizado no estado de Mato Grosso do Sul (17 $15^{\circ} \mathrm{S}$, $20^{\circ} 54^{\prime} \mathrm{W}$ e $55^{\circ} 10^{\prime} \mathrm{S}, 58^{\circ} 12^{\prime} \mathrm{W}$ ) e grande parte de sua área localiza-se na planície do Pantanal, uma região alagável com aproximadamente $140.000 \mathrm{~km}^{2}$, que chama a atenção pela beleza de sua paisagem e da riqueza de plantas e animais silvestres, constituindo uma das maiores e mais diversificadas regiões alagáveis do mundo (Silva \& Junk 1999). É uma área com características extremamente peculiares que definem uma paisagem própria e complexa rede hidrográfica sujeita a inundação periódica (Brasil 1982). O clima do município é tropical, megatérmico, com invernos secos e chuvas no verão. A temperatura média anual é de $25,1^{\circ} \mathrm{C}$, com máximas absolutas atingindo $40^{\circ} \mathrm{C}$, mínimas próximas a $0^{\circ} \mathrm{C}$, umidade relativa média anual de 76,8\% (Soriano 1997) e precipitação média anual oscilando entre 1.000 e 1.400 mm (Cadavid-Garcia 1984).

Para a realização do presente estudo foram examinadas as coleções dos herbários CGMS, CH, COR, MBM, SPF, SPSF e UB (siglas segundo Holmgren et al. 1990). Também foram realizadas coletas na morraria Santa Cruz. As formações vegetacionais são classificadas segundo Veloso (1992).

\section{Resultados e Discussão}

Lauraceae Jussieu, Gen. Pl. 89. 1789.

Árvores ou arbustos, com exceção do gênero Cassytha (trepadeira parasita), monóicas, dióicas ou ginodióicas. Folhas simples, alternas, raro opostas a subopostas, sem estípulas. Inflorescência axilar, raramente terminal, tirsóide, tirsóidepaniculada, racemiforme, raramente capitulada ou reduzida a uma única flor (Rohwer 1993a). As flores são bissexuadas ou unissexuadas com 6 ou 9 tépalas distribuídas em dois, raramente 3 verticilos. Estames com anteras de deiscência valvar, biloceladas ou tetraloceladas, dispostos em 4 verticilos (séries I, II, III e IV), a IV série estaminodial ou ausente, podendo ter 3,6 ou 9 estames férteis, acompanhados ou não de estaminódios (Werff 1991). Gineceu com ovário mediano, súpero, unicarpelar, unilocular e uniovulado; estilete simples, terminal e óvulo pêndulo; fruto em geral bacáceo com exocarpo fino e mesocarpo carnoso (Quinet $\&$ Andreata 2002).

Para o município de Corumbá foram registradas 10 espécies de Lauraceae, subordinadas a cinco gêneros: Aiouea trinervis, Aniba heringerii, Cassytha filiformis, Nectandra amazonum, N. cissiflora, N. gardneri, N. hihua, N. psammophila, Ocotea diospyrifolia e $O$. velloziana.

Foi verificado na maioria dos tratamentos sobre a família no Brasil que Ocotea é o gênero mais rico em espécies (Vicentini et al. 1999, Quinet \& Andreata 2002, Baitello et al. 2003, Quinet 2005), porém, neste trabalho foi encontrada maior riqueza de espécies em Nectandra (5 spp.). Este resultado foi observado também por Killeen (1993) que identificou um maior número de Nectandra (9 spp.) em relação à Ocotea (5 spp.) para a província de Santa Cruz na Bolívia, vizinha ao município de Corumbá.

\section{Chave para identificação dos gêneros de Lauraceae do município de Corumbá}

1. Trepadeiras parasitas com folhas escamiformes

3. Cassytha

1'. Árvores ou arbustos com folhas desenvolvidas.

2. Anteras biloceladas.

3. Estames férteis 9

3'.Estames férteis 6

2'. Anteras tetraloceladas.

4. Locelos dispostos em dois pares sobrepostos

5. Ocotea

4'.Locelos dispostos em linha horizontal ou em arco 
1. Aiouea Aubl. Hist. Pl. Guiane 1: 310, t. 120. 1775 .

Árvores ou arbustos monóicos. Folhas alternas, peninervadas ou 3-plinervadas. Inflorescência paniculada, axilar. Flores bissexuadas, pediceladas, hipanto profundo, obcônico a campanulado, 6 tépalas, eretas mais ou menos iguais, glabras por fora e papilosas por dentro, 6 estames férteis, anteras biloceladas, série I sempre fértil, séries II e III férteis ou estaminodiais, série IV formada por estaminódios triangulares, estipitiformes ou clavados. Pistilo com ovário ovóide ou globoso, estigma discóide. Fruto bacáceo, elipsóide, cúpula de margem inteira.

Aiouea é um gênero neotropical e abriga 19 espécies (Kubitzki \& Renner 1982) sendo 14 registradas no Brasil (Quinet 2005). No Mato Grosso do Sul, o gênero é representado apenas por A. trinervis.

1.1 Aiouea trinervis Meisn. in A. DC., Prodr. 15(1): 83. 1864.

Fig. 1 a-d

Árvores, arbustos até $7 \mathrm{~m}$ alt. Folhas alternas, lâmina 3-10 × 2-7 cm, ovada, ápice obtuso, base aguda, face adaxial glabra, face abaxial com tricomas esparsos, grandes e adpressos, nervuras laterais de 3-5 pares, triplinérvias, pecíolo 10-25 mm compr., glabrescente, canaliculado. Inflorescência ca. $20 \mathrm{~cm}$ compr., panícula, axilar, glabrescente, pedúnculo de 4-8 cm compr. Flores $3 \mathrm{~mm}$ diâm., glabras, urceoladas, tépalas ovadas, estames férteis 6, bilocelados, séries I e II férteis, os da serie III estaminodiais, colunares, série IV com estaminódios triangulares. Pistilo ca. 1,5 mm compr., ovário globoso, glabro, estilete do mesmo tamanho do ovário. Fruto ca. 10 x $5 \mathrm{~mm}$, elipsóide, cúpula ca. $7 \times 5 \mathrm{~mm}$, margem lobada.

Material examinado: BRASIL. MATO GROSSODO SUL: Corumbá, morro do Urucum, 12.VI.1996, fl. e fr., I. M. Bortoloto et al. 328 (COR); idem, 22.VI.1995, fl., G. A. Damasceno-Júnior et al. 840 (COR); idem, 3.VII.1993, fl., L. C. Baracat s.n. (COR 3233); idem, 5.IX.1982, f1., C. A. Conceição s.n. (COR 0237); idem, 4.X.1984, fl., C. A. Conceição 1593 (COR);
18.IX.1996, fl., I. M. Bortoloto \& D. P. Rodriguez 377 (COR); campo de altitude, 11.VII.1992, fl., G. A. Damasceno-Júnior et al. 64 (COR).

Aiouea trinervis ocorre no Brasil nas Regiões Centro-Oeste, Sudeste e Sul (Pedralli 1984), sendo freqüente no cerrado do Mato Grosso do Sul. No município de Corumbá, a espécie é encontrada no campo rupestre na Morraria do Urucum, possuindo aí porte arbustivo, já na floresta estacional semidecidual da morraria Santa Cruz apresenta porte arbóreo. Coletada com flores e frutos entre junho e novembro.

2. Aniba Aubl. Hist. Pl. Guiane 1: 327. 1775. Árvores ou arbustos, monóicos. Folhas alternas, peninervadas. Inflorescência tirsóidepaniculada, axilar ou no ápice dos ramos. Flores bissexuadas, hipanto cupuliforme ou tubular; 6 tépalas eretas, iguais ou sub-iguais; estames férteis 9, anteras biloceladas, séries I, II com filetes em geral mais longos e mais largos que as anteras, locelos apicais-extrorsos, série III subextrorsos, estaminódios da série IV inconspícuos ou ausentes. Pistilo com ovário elipsóide, incluso no hipanto. Fruto elipsóide, liso, cúpula lenhosa e lenticelada.

O gênero é distribuído quase inteiramente na região tropical sul-americana, representado por 41 espécies no neotrópico e 27 no Brasil (Baitello et al. 2003). No Mato Grosso do Sul, o gênero é representado apenas por $A$. heringerii.

2.1 Aniba heringerii Vattimo-Gil, Rodriguésia 23-24: 253. 1961.

Fig. 1 e-g

Árvores até $12 \mathrm{~m}$ alt. Folhas alternas, lâmina $4-15 \times 2-6 \mathrm{~cm}$, elíptica a ovadoelíptica, ápice agudo e base aguda ou obtusa, face adaxial glabra, face abaxial com tricomas esparsos, grandes e adpressos, nervuras laterais de 6-8 pares, nervação broquidódroma, pecíolo 1-14 mm compr., canaliculado. Inflorescência 6-10 cm compr., paniculada, subterminal, pauciflora, em geral mais longa que as folhas, com tricomas 
longos, crespos, adpressos, pedúnculo 2-4 $\mathrm{cm}$ compr. Flores 2-3 mm diâm., hipanto profundo, tépalas ovadas a elípticas subiguais, papilosas na face interna; filetes dos estames das séries I e II iguais, pouco mais largo que as anteras, anteras quadráticas, ápice acuminado, filetes dos estames da série III da mesma largura que a anteras, anteras elípticas, ápice obtuso, série IV com estaminódios liguliformes. Pistilo ca. 1,6 mm compr., ovário elipsóide, estilete do mesmo tamanho a pouco maior que o ovário. Fruto ca. $2 \times 1 \mathrm{~mm}$ compr., elípsoide, cúpula ca. $10 \times 8 \mathrm{~mm}$, lenticelada, pedicelo muito curto a ausente.

Material examinado: BRASIL. MATO GROSSODO SUL: Corumbá, morraria do Acurizal (córrego Chapada), 23.XI.2001, fl., G. A. Damasceno-Júnior et al. 3025 (COR); mata de galeria, 23.XI.2001, fl., $G$. A. Damasceno-Júnior et al. 3024 (COR); córrego Chapada, 23.XI.2001, fl., G. A. Damasceno-Júnior et al. 3025 (COR); idem, 23.XI.2001, fl., G. A. Damasceno-Júnior et al. 3026 (CGMS); córrego Fundão, fazenda Acurizal, 12.XII.2002, fr., E. A. Silveira $5(\mathrm{CH})$.

Segundo Baitello et al. (2003) Aniba heringerii é restrita aos estados do Mato Grosso, Goiás, Distrito Federal, Minas Gerais e São Paulo, sendo coletada na floresta ombrófila densa aluvial e floresta estacional semidecidual no estado de São Paulo. Em Corumbá é encontrada na floresta ombrófila densa aluvial da região da borda oeste do Pantanal, Morraria do Acurizal. Esta é a primeira vez que a espécie é citada para o Mato Grosso do Sul. Coletada com flores em novembro e com frutos em dezembro.

\section{Cassytha L., Sp. Pl. 1: 35. 1753.}

Trepadeira parasita, monóica, com pequenos haustórios. Folhas escamiformes. Inflorescência em geral espiciforme. Flores ca. $2 \mathrm{~mm}$, bissexuadas, sésseis, hipanto profundo, urceolado, 6 tépalas muito desiguais, as externas menores que as internas, 9 estames férteis, anteras biloceladas, estames das séries
I, II e III com filetes delimitados da antera, anteras oval-triangulares, série IV formado por estaminódios triangulares ou glanduliformes. Pistilo $\mathrm{cm}$ ovário fusiforme, glabro. Fruto núcula globosa, envolvido pelo hipanto acrescente.

São reconhecidas 17 espécies de Cassytha para o mundo, sendo a maioria australiana, poucas africanas e asiáticas e apenas Cassytha filiformis é cosmopolita (Weber 1981). No Mato Grosso do Sul, o gênero é representado apenas por esta espécie.

3.1 Cassytha filiformis L., Sp. Pl. 1:35-36. 1753.

Fig. $1 \mathrm{~h}-\mathrm{j}$

Herbácea parasita, ramos filiformes, clorofilados, glabrescentes. Folhas reduzidas a escamas diminutas. Inflorescência espiciforme. Flores ca. 2 mm diâm., hipanto profundo, tépalas muito desiguais, as externas menores que as internas, 9 estames férteis, anteras biloceladas, estames das séries I, II e III com filetes delimitados da antera, anteras oval-triangulares, série IV formado por estaminódios estipitiformes ou subtriangulares. Pistilo 1,5 mm compr., ovário globoso a elíptico, glabro, estilete do mesmo tamanho a levemente menor que o ovário. Fruto 4-7 × 3-5.

Material examinado: BRASIL. MATO GROSSO DO SUL: Corumbá, floresta semidecidual do morro Santa Cruz, 18.VI.1998, fl. e fr., G. A. Fernandes et al. 7 (COR); Jacadigo, 5.VIII.1986, fl. e fr., $R$. Almeida 724 (COR); estrada Parque, 10.VI.1986, fl., R. Almeida 1 (COR); fazenda Nhumirim, 14.VI.1986, fl., S. T. Vasconcellos et al. 344 (COR); mata semidecidual do Jacadigo, 5.VIII.1986, fr., A. Rego 724 (CGMS).

Cassytha filiformis é encontrada na floresta estacional decidual, savana, floresta ombrófila densa aluvial e na restinga (Baitello et al. 2003). Ocorre em todas as subregiões do Pantanal, na savana florestada, floresta estacional semidecidual e na bancada laterítica (Pott \& Pott 1994). Coletada com flores em junho a setembro e com frutos em agosto. 


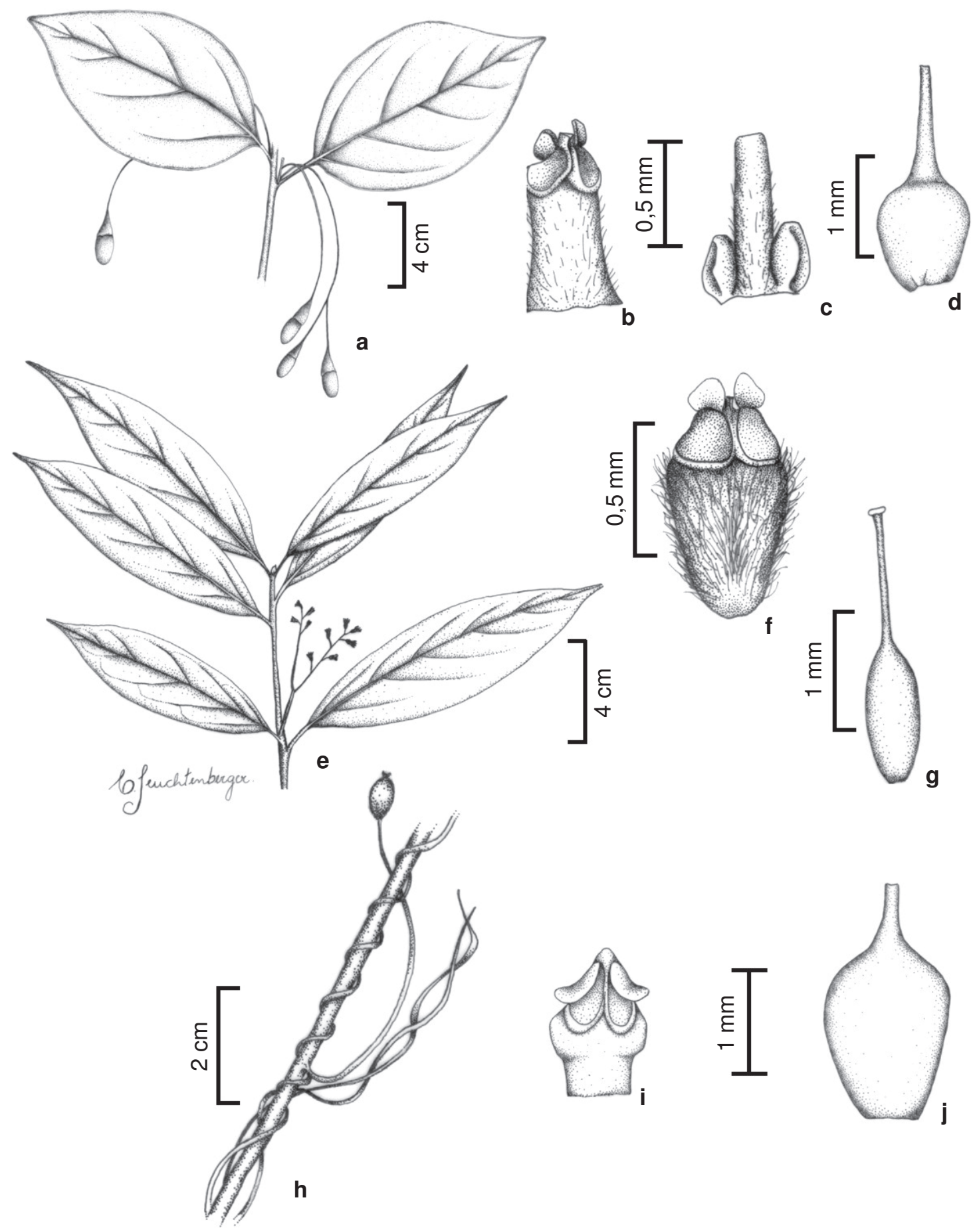

Figura 1 - Aionea trinervis - a. ramo com frutos; b. estame da série I; c. estaminódio da série III; d. pistilo. Aniba heringerii - e. ramo com flores; f. estame da série I; g. pistilo. Cassytha filiformis - h. ramo com fruto; i. estame da série I; j. pistilo. (a-d. Damasceno-Júnior 840; e-g. Damasceno-Júnior 3025; h-j. Vasconcellos 344) 
4. Nectandra Rol. ex Rottb., Acta Lit. Univ. Hafn. 1: 279. 1778.

Árvores monóicas. Folhas alternas, raramente opostas e subopostas, peninervadas. Inflorescência geralmente tirsóide-paniculada, raramente racemiforme, axilar ou no ápice dos ramos. Flores bissexuadas, hipanto raso ou profundo, glabro ou piloso, 6 tépalas, iguais ou subiguais e, em geral, densamente papilosas na face interna; estames férteis 9 , dispostos em 3 séries; anteras tetraloceladas, papilosas, anteras das séries I e II com locelos dispostos em linha horizontal ou em arco, filetes largos, bem delimitados das anteras a inconspícuos, antera da série III com 4 locelos extrorsos ou os superiores dispostos lateralmente, série IV formado por estaminódios reduzidos, filiformes ou ausentes. Ovário globoso a elipsóide, livre. Fruto globoso a elipsóide, cúpula pateliforme a trompetiforme ou hemisférica.

Nectandra é um gênero restrito à América tropical e subtropical, com 114 espécies conhecidas até o presente (Rohwer 1993b) sendo 43 registradas para o Brasil (Baitello et al. 2003). Em Corumbá foram identificadas cinco espécies: $N$. amazonum, $N$. cissiflora, $N$. gardneri, $N$. hihua e N. psammophila.

\section{Chave para identificação das espécies de Nectandra no município de Corumbá}

1. Conectivo das anteras das séries I e II com prolongamento igual ou pouco maior que $50 \%$ do comprimento da antera.

2. Folhas com ambas as faces pubescentes

1. N. amazonum

2'. Folhas com ambas as faces glabrescentes a glabras.

3. Anteras dos estames das séries I e II pentagonais e estames da série II com ápice não contraído; estilete do mesmo tamanho a levemente menor que o ovário, cerca de $1 / 2$ do tamanho do pistilo

3. N. gardneri

3'. Anteras dos estames das séries I e II pentagonais a oval-triangulares e estames da série II com ápice contraído acima dos locelos formando um acume; estilete menor que o ovário, cerca de $1 / 6$ do tamanho do pistilo

4. N. hihua

1'. Conectivo das anteras das séries I e II com prolongamento menor que $45 \%$ do comprimento da antera.

4. Folhas largamente obovadas ou largamente ovadas com face adaxial tomentosa a glabra e face abaxial tomentosa a glabrescente 2. N. cissiflora

4'. Folhas elípticas a ovado-elípticas com face adaxial glabra e abaxial glabrescente

5. N. psammophila

4.1 Nectandra amazonum Nees, Syst. Laur. 282. 1836.

Fig. 2 a-c

Árvores até $20 \mathrm{~m}$ alt. Folhas alternas, lâmina 8-25 × 2-8 cm, lanceolada a oblonga, ápice acuminado, base atenuada, faces abaxial e adaxial pubescente, nervuras larerais de 69 pares, nervação semicraspedódroma, sem domácias, pecíolo 10-21 mm compr., pubescente, canaliculado. Inflorescência $3-5 \mathrm{~cm}$ compr., tirsóide-paniculada, axilar, com tricomas grandes, crespos e adpressos, pedúnculo $2-5 \mathrm{~cm}$ de compr. Flores $7-10 \mathrm{~mm}$ diâm., tépalas desiguais, papilosas na face interna, conectivo dos estames das séries I e II com prolongamento igual ou superior a $50 \%$ do comprimento da antera, filetes dos estames das séries I e II $1 / 5$ da antera ou mais curtos a inconspícuos, anteras pentagonais a oval-triangulares, série III com filetes curtos, anteras subquadráticas, série IV com estaminódios levemente clavados. Pistilo ca. $2 \mathrm{~mm}$ compr., ovário globoso, glabro, estilete levemente menor que o ovário. Fruto ca. $15 \times 10 \mathrm{~mm}$, elíptico, cúpula ca. $13 \times 8,5 \mathrm{~mm}$, campanulada, pedicelo ca. $6,5 \mathrm{~mm}$ compr. 

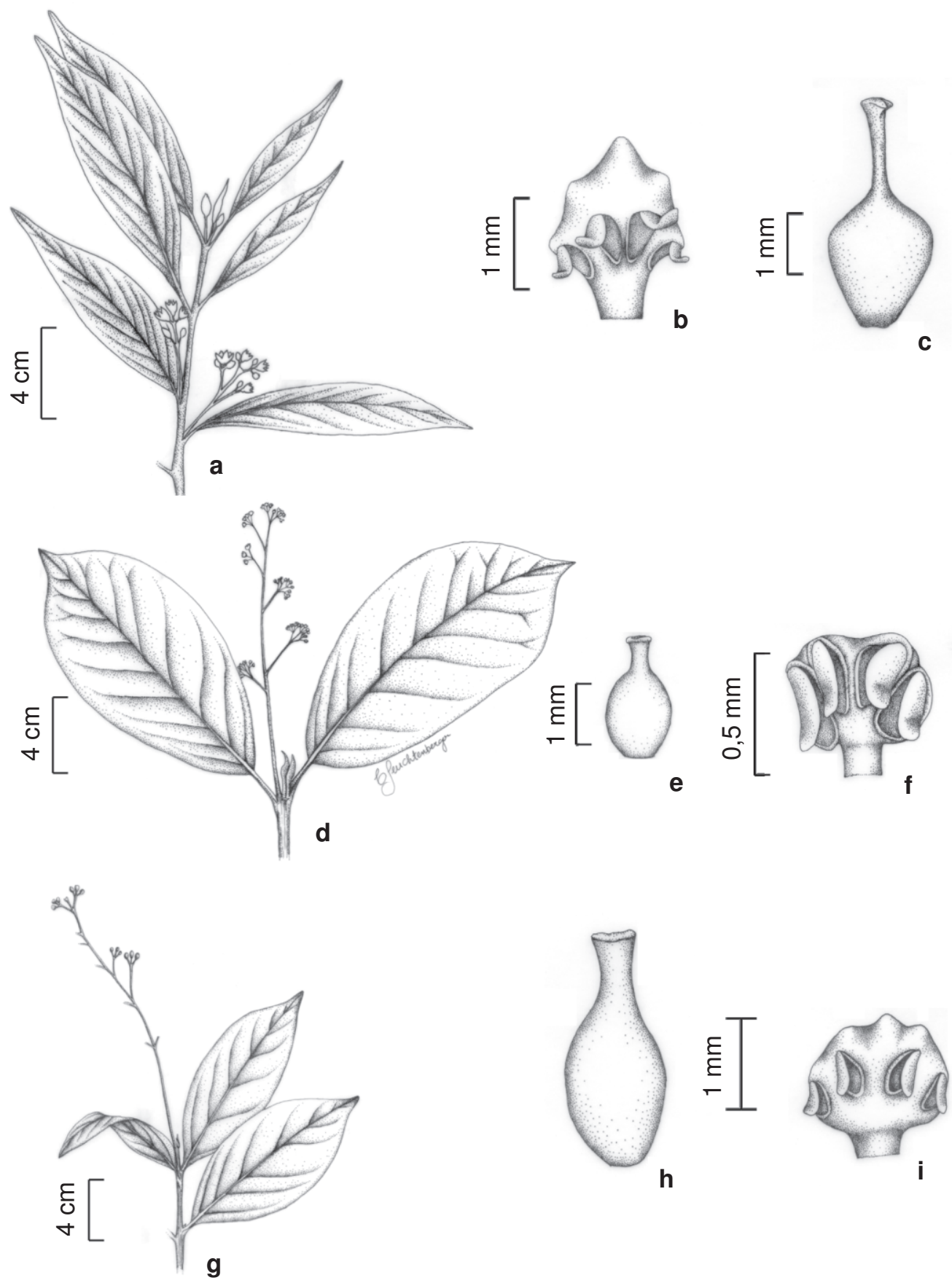

Figura 2 - Nectandra amazonum - a. ramo com flores; b. estame da série I; c. pistilo. N. cissiflora - d. ramo com flores; e. pistilo; f. estame da série I. N. gardneri - g. ramo com flores e fruto; h. pistilo; i. estame da série I. (a-c. DamascenoJúnior 2304; d-f. Solza 84; g-i. Smael 9) 
Material examinado: BRASIL. MATOGROSSODO SUL: Corumbá, mata ciliar do rio Paraguai, 4.V.2001, fl., G. A. Damasceno-Júnior 2304 (COR); idem, 17.X.2002, fl. e fr, I. M. Bortolotto 1140 (COR).

Material adicional: BRASIL. MATO GROSSO: Vila Bela da Santa Trindade, rio Guaporé, 19.VIII.1997, fl., G. Hatschbach et al. 67010 (SPF, MBM). Cáceres, rio Paraguai, 24.VIII.1999, fr., S. I. Castrillon $38(\mathrm{CH})$.

Nectandra amazonum é uma espécie característica da Amazônia brasileira, alcançando o nordeste das Guianas e o sudeste da Bolívia. É provavelmente a mais característica espécie da floresta inundada ao longo do rio Amazonas e seus tributários (Rohwer 1993b), encontrada em toda região norte, e estados do Mato Grosso e Mato Grosso do Sul. Em Corumbá a espécie foi registrada no Pantanal na floresta ombrófila densa aluvial do rio Paraguai. Coletada com flores em maio e com frutos em outubro.

4.2 Nectandra cissiflora Nees, Syst. Laur. 296. 1836.

Fig. 2 d-f

Árvore até $30 \mathrm{~m}$ alt. Folhas alternas, lâmina $12-20 \times 6-12 \mathrm{~cm}$, largamente obovada, largamente elíptica ou largamente ovada, ápice com um curto acumem, base atenuada a obtusa, face adaxial tomentosa a glabra e face abaxial tomentosa a glabrescente, nervuras larerais de 5-8 pares, semicraspedódroma, sem domácias, pecíolo 10-25 mm compr., tricomas densos, curtos e retorcidos, canaliculado. Inflorescência $7-$ $25 \mathrm{~cm}$ compr., tirsóide-paniculada, axilar, puberulenta, geralmente maior ou excedendo as folhas, pedúnculo 6-10 cm compr. Flores 4-5 mm diâm., pubérulas, tépalas subiguais, elípticas, densamente papilosas na face interna e na extremidade; conectivo dos estames das séries I e II com prolongamento não superior a $45 \%$ do comprimento da antera, filetes dos estames das séries I e II muito curtos ou inconspícuos, anteras transverso-elípticas, ápice arredondado, densamente papilosos na face abaxial; filetes dos estames da série III curtos, anteras subquadráticas a obtrapeziformes, ápice truncado, série IV com estaminódios subclavados; pistilo ca. $1 \mathrm{~mm}$ compr., glabro, ovário globoso a elíptico, glabro, estilete menor que o ovário. Fruto ca. $18 \times 10 \mathrm{~mm}$, elipsóide a globoso, cúpula ca. $2 \times 10 \mathrm{~mm}$, trompetiforme, pedicelo ca. 1,7 cm compr. Material examinado: BRASIL. MATO GROSSODO SUL: Corumbá, morro Santa Cruz, 9.XI.1999, fl., S. S. Solza 84 (COR); idem, 18.VI.1998, fl., G. A. Fernandes 7 (COR); idem, 20.VII.2004, fl., F. M. Alves \& I. H. Ishii 33 (COR).

Material adicional: BRASIL. MATO GROSSO DO SUL: Rochedo, córrego Rochedo, 28.VIII.1988, fl., G. A. Damasceno-Júnior 1547 (CGMS). Rio Negro, rio do Peixe, 26.VIII.1988, fr., V. J. Pott et al. 3507 (CGMS); idem, rio do Garimpo, 26.VIII.1988, fr., V. J. Pott et al. 3555 (CGMS).

Nectandra cissiflora é encontrado nas Regiões Centro-Oeste, Sudeste e Sul, na floresta estacional semidecidual, floresta ombrófila densa aluvial e savana florestada (Baitello et al. 2003). Em Corumbá, é encontrada apenas na floresta estacional semidecidual da Morraria Santa Cruz. Coletada com flores de junho a setembro.

4.3 Nectandra gardneri Meisn., Prod.15 (1): 155. 1864.

Fig. 2 g-i

Árvore ou arbustos até $10 \mathrm{~m}$ alt. Folhas alternas, lâmina 6,5-19,5 × 3-8,5 cm, ovada, largo-ovada, largo-elíptica, ovado-elíptica, raro lanceolada, ápice acuminado, base levemente atenuada, face adaxial e abaxial glabrescente, nervuras laterais de 5-8 pares, broquidódroma, domácias nas axilas das nervuras laterais em forma de tufos de tricomas, pecíolo 5-19 mm compr., com tricomas curtos, numerosos e adpressos, canaliculado. Inflorescência 9-20 cm compr., tirsóide-paniculada, axilar, coberto por tricomas grandes, retorcidos e eretos, com comprimento igual ou menor que as folhas, pedúnculo 3,5-9,2 cm compr. Flores 7-9 mm diâm., tépalas elípticas a ovadas, densamente papilosas na face interna e na extremidade, conectivo dos estames das séries I e II com prolongamento igual ou superior a $50 \%$ do comprimento da antera, filetes dos estames 
das séries I e II 1/5 da antera ou mais curtos, anteras pentagonais com ápice agudo, arredondado a truncado, anteras da série III obtrapeziformes com ápice obtuso a truncado, série IV com estaminódios triangulares. Pistilo ca. 2,2 mm compr., ovário globoso, glabro, estilete do mesmo tamanho a levemente menor que o ovário. Fruto ca. $12 \times 8 \mathrm{~mm}$, elíptico, cúpula ca. $5,5 \times 8,5 \mathrm{~mm}$, trompetiforme, pedicelo ca. $6,5 \mathrm{~mm}$ compr.

Material examinado: BRASIL. MATO GROSSO DO SUL: Corumbá, morro com mata semidecídua, 13.VI.2002, fl. e fr., J. Smael et al. 9 (COR).

Material adicional: BRASIL. MATO GROSSO DO SUL: Campo Grande, reserva biológica da UFMS, 8.VI.1988, fl., M. Carmo 4 (CGMS); idem, 15.IX.1988, fl., W. G. Silva 126 (CGMS); idem, 30.IV.1990, fr., U. M. Resende 93 (CGMS); idem, 21.III.1992, fl., K. N. Cação 22 (CGMS); idem, 18.IV.1988, fr., W. S. Silva 126 (CGMS).

Nectandra gardneri é encontrada no cerrado do Brasil, na floresta ombrófila densa aluvial, entre 400 e $1000 \mathrm{~m}$ de altitude (Rohwer 1993b). No município de Corumbá, ocorre na floresta estacional semidecidual. Coletada com flores e frutos em abril.

4.4. Nectandra hihua (Ruiz \& Pav.) Rohwer, Fl. Neotrop. 60: 196. $1993 . \quad$ Fig. 3. a-d

Árvore até $14 \mathrm{~m}$ alt. Folhas alternas, lâmina 5-26 × 2-9,5 cm, ovada, ovadoelíptica, largo-elíptica a lanceolada, ápice acuminado, base curtamente atenuada e geralmente revoluta, face adaxial glabrescente a glabra, face abaxial glabrescentes, nervuras laterais de 6-8 pares, eucampdódroma, presença de domácias nas axilas das nervuras laterais, em forma de tufos de tricomas em algumas folhas, pecíolo 10-20 $\mathrm{mm}$ compr., glabrescente, plano. Inflorescência 5-15 cm compr., tirsóide-paniculada, axilar, com tricomas curtos, levemente crespos e numerosos a esparsos, comprimento igual ou menor que as folhas, pedúnculo 2-9,5 cm compr. Flores 6-12 mm diâm., tricomas curtos e mais densos no receptáculo, diminuindo em direção as tépalas, glabrescente no ápice; receptáculo em forma de cálice, tépalas elípticas a ovadas, raramente pentagonais, densamente papilosas na face interna e na extremidade; conectivo dos estames das séries I e II com prolongamento igual ou superior a $50 \%$ do comprimento da antera e papiloso, filetes dos estames das séries I e II 1/5 da antera ou mais curtos a inconspícuos, anteras dos estames da série I pentagonais a ovaltriangulares, ápice obtusos a levemente agudo, antera dos estames da série II ovaltriangulares com ápice contraído acima dos locelos formando um acume, série III obtrapeziformes com ápice obtuso a truncado, estaminódios evidentes. Pistilo ca. 2,3 mm compr., ovário globoso, glabro, estilete muito curto, cerca de $1 / 6$ do tamanho do pistilo. Fruto ca. $13 \times 8 \mathrm{~mm}$, globoso a elíptico, cúpula ca. $2 \times 6 \mathrm{~mm}$, pateriforme, pedicelo ca. $1,1 \mathrm{~cm}$ compr., atenuado na base.

Material examinado: BRASIL. MATO GROSSO DO SUL: Corumbá, morro do Urucum, 9.IX.1984, fl., F. Bucci 1578 (COR); morro da Tromba dos Macacos, 9.IX.1984, fl., C. A. Conceição 1578 (CGMS, COR, UB).

Material adicional: BRASIL. MATO GROSSO DO SUL: Campo Grande, fazenda Santa Inês, 14.VIII.1990, fl., U. M. Resende 129 (CGMS); Guariroba, 2.X.1997, fl., U. M. Resende 1366 (CGMS). Bodoquena, 23.V.2002, fl., U. M. Resende 983 (CGMS). Rio Brilhante, BR 163, 9.VII.2001, fl., A. Sciamarelli 877 (CGMS). Bonito, fezenda Pitangueiras, 10.IX.2001, fl., G. P. Nunes et al. 2 (CGMS). Dourados, estrada para Maracaju, 27.IX.2001, fr., A. Sciamarelli et al. 1049 (CGMS).

Nectandra hihua é encontrada do oeste do México e Antilhas até a região noroeste do estado de São Paulo, na floresta estacional semidecidual, solos úmidos, periodicamente inundados ou encharcados (Baitello et al. 2003). Em Corumbá, ocorre na floresta estacional semidecidual e floresta ombrófila densa aluvial do morro do Urucum. Coletada com flores em setembro. 
4.5. Nectandra psammophila Nees \& C. Mart., Syst. Laur. 303. $1836 . \quad$ Fig. 3 e-f

Árvore até $12 \mathrm{~m}$ alt. Folhas alternas, lâmina 5-12 × 2,5-3,5 cm, elíptica a ovadoelíptica, ápice acuminado, base atenuada, face adaxial glabra e face abaxial glabrescente, nervuras laterais de 6-10 pares, broquidódroma, sem domácias pecíolo 5-10 $\mathrm{mm}$ compr., tricomas curtos, adpressos e esparsos, canaliculado. Inflorescência 5-7 cm compr., racemiforme, axilar, com tricomas curtos, adpressos e esparsos, pedúnculo 2-4 $\mathrm{cm}$ compr. Flores 5-6 cm diâm., tépalas elípticas a ovadas, as externas menos denso-papilosas que as internas; conectivo dos estames das séries I e II com prolongamento não superior a $45 \%$ do comprimento da antera, filetes dos estames das séries I e II inconspícuos, filetes dos estames das séries I e II 1/5 da antera ou mais curtos a inconspícuos, série III com anteras quadrangulares a obtrapeziformes, série IV com estaminódios subclavados. Pistilo ca. 1,8 mm compr., ovário globoso a elíptico, glabro, menor que o ovário. Fruto ca. $10 \times 8 \mathrm{~mm}$, elíptico, cúpula ca. $7 \times 4 \mathrm{~mm}$ compr., trompetiforme, pedicelo ca. $6,5 \mathrm{~mm}$ compr. Material examinado: BRASIL. MATO GROSSODO SUL: Corumbá, Jacadigo, 29.VI.1997, fl., fr., S. R. S. Pereira 2 (COR).

Nectandra psammophila é encontrada no Brasil do sul da Bahia até São Paulo, na vegetação arbórea de vales e planícies litorâneas associadas ou não a floresta ombrófila densa aluvial (Baitello et al. 2003). Segundo Killen (1993), a espécie é encontrada também em floresta estacional semidecidual na Bolívia. Em Corumbá, a espécie foi encontrada na floresta estacional semidecidual da região do Jacadigo. Coletada com flores e frutos em junho.

\section{Ocotea Aubl., Hist. Pl. Guiane 2: 781. 1775.}

Árvores ou arbustos, monóicos, dióicos ou gimnodióicos. Folhas alternas, raramente opostas ou subopostas, peninérveas. Inflorescência tirsóide-paniculada ou racemiforme. Flores unissexuadas, bissexuadas ou polígamas, tépalas iguais ou subiguais, geralmente eretas na antese, 9 estames férteis, anteras das séries I, II e III tetraloceladas, estaminodiais nas flores femininas, locelos dispostos em dois pares sobrepostos, séries I e II geralmente introrsos, série III com locelos inferiores extrorsos, os superiores laterais extrorsos. Pistilóide da flor masculina estipitiforme, conspícuo a ausente. Fruto bacáceo, globoso a elíptico, cúpula envolvendo o fruto em proporções variáveis, tépalas caducas ou podendo persistir no fruto.

Ocotea possui aproximadamente 350 espécies, sendo a maioria encontrada na América tropical e subtropical, cerca de 50 espécies ocorre em Madagascar, sete nas Antilhas e uma nas Ilhas Canárias (Baitello et al. 2003). Em Corumbá foram registradas duas espécies: $O$. diospyrifolia e $O$. velloziana. Pott \& Pott $(1994,1999)$, também referiram às mesmas espécies para a região do Pantanal.

\section{Chave para identificação das espécies de Ocotea no município de Corumbá}

1. Filetes dos estames das séries I e II 1/5 a 1/4 do comprimento da antera, sésseis a sub-sésseis; folhas lanceoladas a elípticas 1.Ocotea diospyrifolia

1'. Filetes dos estames das séries I e II 1/3 a 1/2 do comprimento da antera; folhas largo-elípticas, ovadas a obovadas 2. Ocotea velloziana 

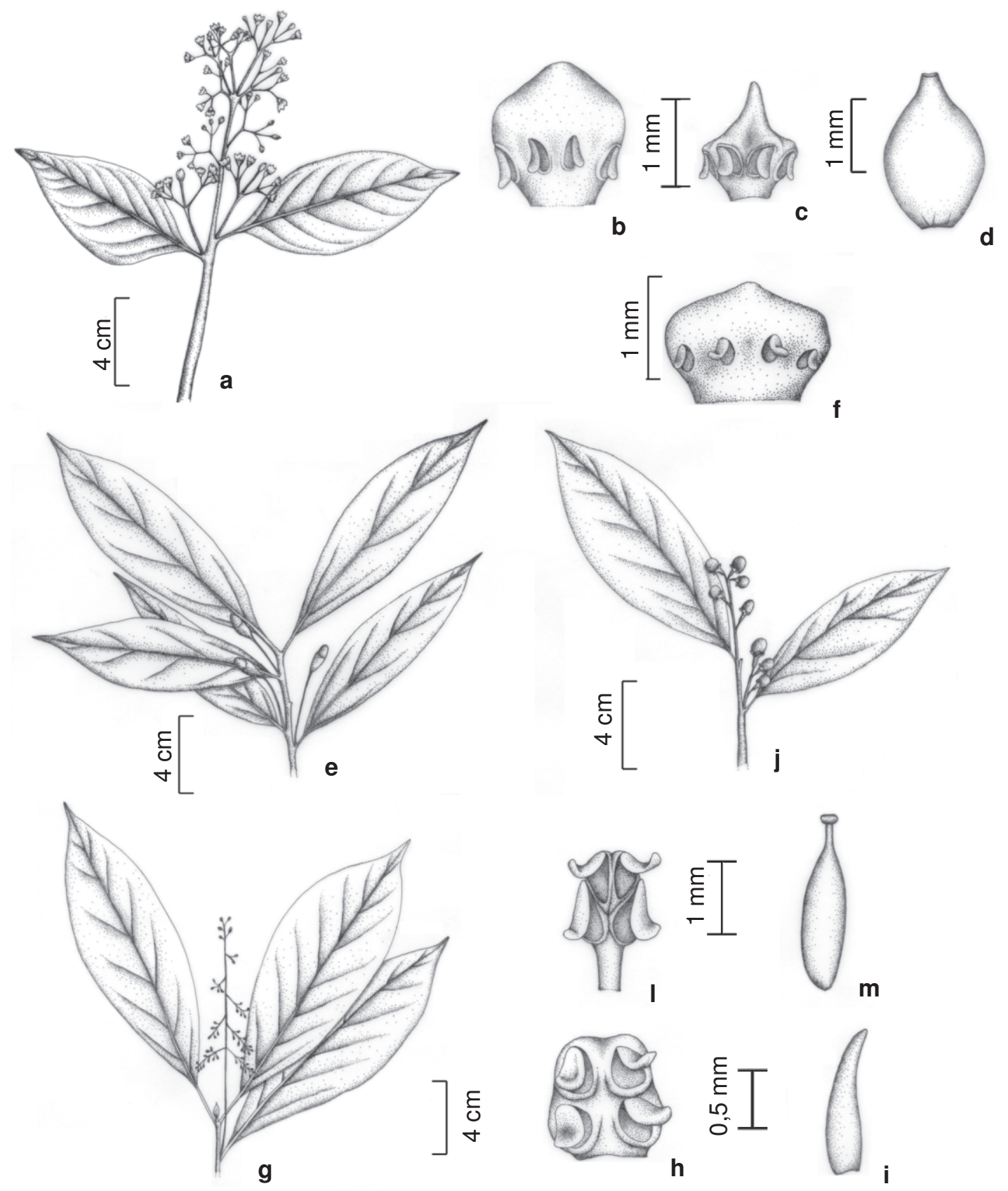

Figura 3 - Nectandra hihua - a. ramo com flores; b. estame da série I; c. estame da série II; d. pistilo. N. psammophila e. ramo com frutos; f. estame da série I. Ocotea diospyrifolia - g. ramo com flores; h. estame da série I; i. pistilódio. O. velloziana - j. ramo com frutos; 1. estame da série I; m. pistilódio. (a-d. Bucci 1578; e-f. Pereira 2; g-i. Castro 9; $\mathrm{j}-\mathrm{m}$. Resende 185) 
5.1. Ocotea diospyrifolia Mez, Jahrb. Königl. Bot. Gart. Berlin 5: 374. $1889 . \quad$ Fig. 3 g-i Árvore dióica, até $18 \mathrm{~m}$ alt. Folhas alternas, lâmina 5-15 × 2-4 cm, lanceolada a elíptica, face adaxial brilhante, abaxial fosca, nervuras laterais de 5-9 pares, pecíolo 10-19 $\mathrm{mm}$ de comprimento, glabrescente, canaliculado. Inflorescência ca. $10 \mathrm{~cm}$ compr., paniculada, axilar, glabrescente. Flores unissexuadas, tépalas ovadas a elípticas, mais ou menos iguais, flores masculinas com estames das séries I e II com filetes mais curtos em relação às anteras, 1/4 a 1/5 de seu comprimento, sésseis a subsésseis, anteras quadrangulares a retangulares, estames da série III com anteras retangulares a ovaladas, locelos superiores lateral-introrso, os inferiores lateral-extrorso, pistilo estéril e filiforme, flores femininas com ovário globoso, glabro, estilete menor que o ovário. Fruto ca. $15 \times 10 \mathrm{~mm}$, elipsóide, cúpula ca. $6 \times 13 \mathrm{~mm}$, trompetiforme. Material examinado: BRASIL. MATO GROSSO DO SUL: Corumbá, mata ciliar do rio Paraguai, 9.IX.1994, fl. fem. e fr., G. A. Damasceno-Júnior 387 (COR); idem, 30.VII.1982, fl. fem., E. J. Paula \& C. A. Conceição 1567 (COR); idem, 7.VI.1982, fl. fem., E. J. Paula \& C. A. Conceição 1588 (COR); idem, 25.XI.2001, fl. masc., G. A. Damasceno-Júnior 3093 (COR); área de inundação do rio Paraguai, 9.VI.2001, fl. masc., $E$. G. Castro et al. 9 (COR); margem do Tamengo, 8.VII.1984, fr., C. A. Conceição 1507 (CGMS); Passo do Lontra, 7.VII.1991, fr., U. M. Resende et al. 489 (CGMS).

Ocotea diospyrifolia ocorre na Argentina, Paraguai e no Brasil nas regiões Centro-Oeste, Sudeste e Sul, na floresta estacional semidecidual e floresta ombrófila densa aluvial (Baitello et al. 2003). No município de Corumbá, a espécie é freqüentemente encontrada na floresta ombrófila densa aluvial do rio Paraguai e segundo Pott \& Pott (1994), pode ser encontrada em todas as subregiões do Pantanal, em capões, borda de cordilheira, solos arenosos e argilosos. Coletada com flores de junho a novembro e com frutos de julho a novembro.
5.2. Ocotea velloziana (Meisn.) Mez, Jahrb. Königl. Bot. Gart. Berlin 5: 347. 1889.

Fig. $3 \mathrm{j}-\mathrm{m}$

Árvore dióica, até $12 \mathrm{~m}$ alt. Folhas alternas, lâmina 6-15×3-7 cm, largo-elíptica, obovada ou ovada, face adaxial glabrescente, ou com tricomas esparsos, face abaxial tomentosa, nervuras laterais de 7-11 pares, pecíolo 12-20 mm compr., glabrescente, canaliculado. Inflorescência ca. $12 \mathrm{~cm}$ compr., panículada, axilar, tomentosa. Flores unissexuadas, tépalas ovadas a elípticas, mais ou menos iguais, flores masculinas com tépalas ovadas, filetes dos estames das séries I e II, $1 / 3$ a 1/2 do comprimento das anteras, estreitos, glabrescentes, anteras ovadoretangulares a ovadas, filetes dos estames da série III largos, do mesmo tamanho das anteras, anteras retangulares, pistilo estéril e filiforme, flores femininas com ovário globoso a elipsóide, estilete robusto. Fruto ca. $8 \times 7$ $\mathrm{mm}$, globoso e brilhante, cúpula ca. $3 \times 5 \mathrm{~mm}$, plana, margem lobada.

Material examinado: BRASIL. MATO GROSSODO SUL: Corumbá, mata ciliar do rio Paraguai, s.d., fl. masc., A. Pott 4678 (CPAP); mata ciliar, s.d., veg., A. Pott s.n. (CPAP 7994).

Material adicional: BRASIL. MATO GROSSO DO SUL: Campo Grande, bairro Coopharadio, 7.IX.1986, fr., C. A. Conceição 1920 (CGMS); bairro Rita Vieira, 25.VIII.1988, fl. masc., C. A. Conceição 2352 (CGMS); Reserva-UFMS, 23.VI.1988, fl. masc., U. M. Rezende 7 (CGMS). Bodoquena, fazenda California, 23.V.2002, fl. fem., S. Aragaki \& U. M. Rezende 952 (CGMS). Aquidauana, estrada de Bonito, 14.IX.1990, fl. masc., U. M. Rezende 185 (CGMS). Bonito, estrada Bonito-Campo Grande, 4.IX.1988, fl. masc., U. M. Rezende 184 (CGMS).

Ocotea velloziana é encontrada nas Regiões Nordeste, Centro-Oeste, Sudeste e Sul, na savana, savana florestada e floresta ombrófila densa aluvial (Baitello et al. 2003). Segundo Pott \& Pott (1994) a espécie é encontrada no município de Corumbá, junto aos rios que descem o Pantanal, na floresta ombrófila densa aluvial, capões de vazante e borda de coronal. 


\section{Agradecimentos}

Os autores agradecem ao especialista Dr. João Batista Baitello do Instituto Florestal de São Paulo pelo envio de bibliografia e valiosos esclarecimentos sobre a morfologia e distribuição geográfica do grupo. Aos curadores dos herbários pelo apoio logístico e empréstimo de exsicatas. À Caroline Leuchtenberger pela confecção das ilustrações.

\section{REFERÊNCIAS BibliográFicas}

Alves, J. L. H. \& Paula, J. L. 1997. Madeiras Nativas; anatomia, dendrologia, dendrometria, produção e uso. Ed. Gutenberg, Brasília, 541p.

Baitello, J. B. 2001. Novas espécies de Lauraceae para a flora brasileira. Acta Botanica Brasilica 14(3): 445-450.

Baitello, J. B.; Hernández, F. G. L.; Moraes, P. L. R.; Esteves, R. \& Marcovino, J. R. 2003. Lauraceae. In: Wanderley, M. G. L.; Shepherd, G. J.; Giulietti, A. M.; Melhem, T. S. (eds). Flora Fanerogâmica do Estado de São Paulo. vol. 3. FAPESP/ Rima, São Paulo. Pp. 149-223.

Barroso, G. M.; Guimarães, E. F.; Ichaso, C. L. F.; Costa, C. G. \& Peixoto, A. L. 2002. Sistemática de Angiospermas do Brasil. v.1, 2a ed. Universidade Federal de Viçosa, Viçosa, 255p.

Brasil. 1982. Ministério das Minas e Energia. Secretaria Geral. Projeto RADAMBRASIL. Folha SE.21. Corumbá e parte da Folha SE. 20: geologia, geomorfologia, pedologia, vegetação e uso da terra. Rio de Janeiro, 452p. (Levantamento de Recursos Naturais, 27).

Cadavid-Garcia, E. A. 1984. O clima no Pantanal Matogrossense. EmbrapaPantanal, Corumbá, Circular Técnica 14, 39p.

Dubs, B. 1998. The Botany of Mato Grosso: Checklist of Angiosperms. séries B, n.3. Betrona-Verlag, 139p.
Holmgren, P. K.: Holmgren, N. H. \& Barnett, L. C. 1990. Index Herbariorum: The herbaria of the world. New York Botanical Garden, New York, 693p.

Judd, W. S.; Campbel, C. S.; Kellogg, E. A. \& Stevens, P. F. 1999. Plant systematics: a phylogenetic approach. Sinauer Associates, Inc., Massachusetts, 792p.

Killeen, T. J. 1993. Lauraceae. In: Killeen, T. J; Garcia, E. E. \& Beck, S. G. (eds.). Guia de arboles de Bolivia. MBG, La Paz. Pp. 368-387.

Kubitzki, K. \& Renner, S. 1982. Lauraceae: Aniba and Aiouea. Flora Neotropica Monograph 31: 85-124.

Pedralli, G. A. 1984. Família Lauraceae no Rio Grande do Sul, Brasil: gênero Aiouea Aubl. Iheringia 32: 15-21.

Pott, A. \& Pott, V. J. 1994. Plantas do Pantanal. Embrapa, Brasília, 320p. 1999. Flora do Pantanal; Listagem atual de Fanerógamas. In: Anais do Simpósio Sobre Recursos Naturais e Sócio-Econômicos do Pantanal 2, Manejo e Conservação. Corumbá, MS. Embrapa Pantanal, Corumbá. Pp. 297-325.

Quinet, A. \& Andreata, R. H. P. 2002. Lauraceae Jussieu na Reserva Ecológica de Macaé de Cima, município de Nova Friburgo, RJ, Brasil. Rodriguésia 53(82): 59-121.

Quinet, A. 2005. Sinopse taxonômica da família Lauraceae no estado do Rio de Janeiro, Brasil. Acta Botânica Brasílica 19: 563-572.

Rohwer, J. G. 1993a. Lauraceae. In: Kubitzki K., Rohwer J. G. \& Bittrich V. (eds). The families and genera of vascular plants. vol. 2. Magnoliid, Hamameliid ad Caryophyliid families. Springer-Verlag, Berlin. Pp. 336-391.

1993b. Lauraceae: Nectandra. Flora Neotropica Monograph 60: 1-332.

Silva, C. J. \& Junk, W. J. 1999. O conceito do pulso de inundação e suas aplicações para 
o Pantanal do Mato Grosso. In: Simpósio sobre recursos naturais e sócio-econômicos do Pantanal 2; Manejo e conservação. 1996, Corumbá, MS. Anais... EmbrapaPantanal, Corumbá. Pp. 17-28.

Soriano, B. M. A. 1997. Caracterização climática de Corumbá-MS. EmbrapaPantanal, Corumbá, 25p. (Boletim de Pesquisa. 11).

Veloso, H. P. 1992. Manual técnico da vegetação brasileira. IBGE, Rio de Janeiro, 93p.

Vicentini, A.; van der Werff, H. \& Nicolau, S. 1999. Lauraceae. In: Ribeiro, J. E. L. S.; Hopkins, M. J. G.; Vicentini, A.; Sothers, C. A.; Costa, M. A. S.; Brito, J.
M.; Solza, M. A.; Martins, L. H. P.; Lohmann, L. G.; Assunção, P. A. C. L.; Pereira, E. C.; Silva, C. F. Mesquita, M. R.; Procópio, L. C (orgs). Flora da Reserva Ducke. Guia de identificação das plantas vasculares de uma floresta de terra-firme na Amazônia Central. INPA, Manaus. Pp. 150-179.

Weber, J. Z. 1981. A taxonomic revision of Cassytha (Lauraceae). Australia Journal of the Adelaide Botanic Gardens 3: 187-262.

Werff, H. van der. 1991. A key to the genera of Lauraceae in the new world. Annals Missouri Botanical Garden 78(2): 377-387. 